\title{
Relationships of Cold Acclimation and Antioxidative Enzymes with Chilling Tolerance in Cucumber (Cucumis sativus $\mathbf{L}$.
}

\author{
Yong In Kuk ${ }^{1}$ \\ Biotechnology Research Institute, Chonnam National University, Gwangju 500-757, Korea \\ Jae Hong Lee, Han Yong Kim, Soon Ju Chung, Gap Chae Chung, and Ja Ock Guh \\ Faculty of Applied Plant Science, Chonnam National University, Gwangju 500-757, Korea \\ Hee Jae Lee \\ School of Plant Science, Seoul National University, Suwon 441-744, Korea \\ Nilda R. Burgos \\ Department of Crop, Soil, and Environmental Science, University of Arkansas, Fayetteville, AR 72704
}

\begin{abstract}
AdDitional INDEX wORDs. chilling injury, chlorophyll a fluorescence, isozyme profile, lipid peroxidation
Abstract. To determine whether chilling tolerance is related to cold acclimation, changes in physiological responses and activity of antioxidative enzymes were investigated in leaves of cucumber (Cucumis sativus $\mathrm{L}$.) grown in controlled environments. Plants were exposed to $15^{\circ} \mathrm{C}$ (cold-acclimated) or $25^{\circ} \mathrm{C}$ (nonacclimated) for 3 days, under $50 \mu \mathrm{mol}^{\prime} \cdot \mathrm{m}^{-2} \cdot \mathrm{s}^{-1}$ photosynthetic photon flux and $70 \%$ relative humidity. Plants were then exposed to $8^{\circ} \mathrm{C}$ chilling temperature for 3 days, and allowed to recover in a growth chamber at $25^{\circ} \mathrm{C}$ for 3 days. Measurements of leaf water content, cellular leakage, lipid peroxidation, chlorophyll a fluorescence, and quantum yield showed that cold-acclimated leaves were less affected by chilling compared to nonacclimated leaves. Cold-acclimated leaves recovered faster than nonacclimated leaves with regard to all variables examined. Catalase and ascorbate peroxidase activities were induced in cold-acclimated leaves, but not in nonacclimated leaves. These data indicate that cold acclimation increased chilling tolerance of cucumber in association with antioxidative enzymes.
\end{abstract}

Crops of tropical and subtropical origins are now cultivated in areas where temperatures may be below the optimum required for their normal growth and development. Like other thermophilic crops, cucumber (Cucumis sativus) is susceptible to chilling temperatures (Wang, 1990). One method used to improve cold tolerance in plants is cold acclimation (Salveit and Morris, 1990). This technique entails exposure of chilling-sensitive tissue to temperatures slightly above chilling for a certain period of time. Cold acclimation can reduce injury caused by chilling temperature (Gilmour et al., 1988). Acclimation of chilling-sensitive plants, such as maize (Zea mays L.) and tomato (Lycopersicon esculentum [L.] Mill.), to low temperature reduces chilling injury (Anderson et al., 1995; Venema et al., 2000). Although mechanisms of chilling injury and tolerance have been studied in cucumber plants (Erez et al., 2002; Reyes and Jennings, 1994; Terashima et al., 1994), little is known about the role of antioxidative enzymes in chilling tolerance.

Various mechanisms have been suggested to account for chilling injury or tolerance in plants (Basra, 2001; Lee and Lee, 2000; Wise and Naylor, 1987). Active oxygen species (AOS), such as superoxide $\left(\mathrm{O}_{2} \cdot{ }^{-}\right)$, hydrogen peroxide $\left(\mathrm{H}_{2} \mathrm{O}_{2}\right)$, hydroxyl radical $(\mathrm{OH} \cdot)$, and singlet oxygen $\left({ }^{1} \mathrm{O}_{2}\right)$, may be produced under low temperatures due to chilling-induced photoinhibition (Havaux and Davaud, 1994; Terashima et al., 1994). Plants have also evolved mechanisms to protect cellular membranes and organelles from the damaging effects of AOS (Foyer et al., 1991). Antioxidative enzymes and antioxidant molecules can neutralize AOS (Foyer

Received for publication 7 Nov. 2002. Accepted for publication 19 May 2003. This work was supported by the Korea Research Foundation Grant (KRF-99005-G0002).

1'Corresponding author; e-mail yikuk@chonnam.ac.kr. et al., 1991; Lee and Lee, 2000; Oidaira et al., 2000; Scandalios, 1993; Wise and Naylor, 1987).

Cold acclimation increases tolerance to AOS in cereals and correlates with an increase in antioxidative enzymes (Anderson et al., 1995; Scebba et al., 1999). In chilling-sensitive plants, the ability to defend against oxidative damage is directly correlated with the level of antioxidants such as ascorbate, glutathione, and $\alpha$-tocopherol (Wise and Naylor, 1987), and the activities of antioxidative catalase (CAT; Upadhyaya et al., 1989), superoxide dismutase (SOD) (Michalski and Kaniuga, 1982), and glutathione reductase (GR) (Foyer et al., 1991). Thus, it is important to determine the activities of various antioxidative enzymes during acclimation and chilling to assess their contribution to chilling tolerance.

The objectives of this study were to compare the physiological responses of cold-acclimated and nonacclimated cucumber plants to chilling and the ability of cucumber plants to recover from chilling injury. Leaf wilting, membrane damage, and photosynthetic efficiency were measured to estimate chilling injury. Furthermore, activities of antioxidative enzymes and their isozymes were compared in cold-acclimated and nonacclimated cucumber plants to examine if the enzymes are associated with chilling tolerance.

\section{Materials and Methods}

Plant growth and treatment conditions. 'Naeseo Samchuk' cucumber seeds were obtained from Seminis Korea Co., Ltd. (Seoul, Korea). Seeds were sown in plug trays $(50 \times 30 \times$ $7 \mathrm{~cm}$ ) containing commercial soil substrate (Boo-Nong Soil, Seoul, Korea) and allowed to germinate in the greenhouse at 30 $\pm 3{ }^{\circ} \mathrm{C} / 20 \pm 3{ }^{\circ} \mathrm{C}$ day/night temperature. Germinated seedlings 
were transplanted to a 500-mL pot containing commercial soil substrate, and placed in the growth chamber until plants reached three-leaf stage. The growth chamber was maintained at $30^{\circ} \mathrm{C} / 25$ ${ }^{\circ} \mathrm{C}$ day/night temperature, 14 -h photoperiod, and $70 \%$ relative humidity. Light period started at $0600 \mathrm{HR}$. The photosynthetic photon flux (PPF) on the plant canopy was $250 \mu \mathrm{mol} \cdot \mathrm{m}^{-2} \cdot \mathrm{s}^{-1}$. The seedlings were watered daily and supplied with half-strength Hoagland's nutrient solution $3 \mathrm{~d}$ before treatment.

At the three-leaf stage the plants were acclimated at 15 or $25^{\circ} \mathrm{C}$ for $3 \mathrm{~d}$ under a 14-h photoperiod with an irradiance of 50 $\mu \mathrm{mol} \cdot \mathrm{m}^{-2} \cdot \mathrm{s}^{-1}$. The acclimated plants were exposed to chilling at $8^{\circ} \mathrm{C}$ for $3 \mathrm{~d}$. After the chilling treatment, plants were allowed to recover for $3 \mathrm{~d}$ under a $14-\mathrm{h}$ photoperiod with $50 \mu \mathrm{mol} \cdot \mathrm{m}^{-2} \cdot \mathrm{s}^{-1} \mathrm{PPF}$ at 25 ${ }^{\circ} \mathrm{C}$. Measurements of physiological variables were taken from the second leaf from the bottom of each plant, $7 \mathrm{~h}$ after the onset of light period, from the start of low temperature acclimation to the third day of recovery. Acclimation and stress treatments were also imposed $7 \mathrm{~h}$ after onset of light period. Harvesting was done at the same time each day to avoid complications from diurnal fluctuations in biochemical processes. Since chilling injury in cucumber plants usually occurs in the dawn or in the early morning, the plants were subjected to low light condition throughout the experiment. The experiments were at least triplicated each with six plants.

Evaluation of Chilling INJURY. Chilling injury on leaves was evaluated using several variables. Since typical visual symptom of chilling injury is wilting of leaves (Salveit and Morris, 1990), leaf water content was examined during acclimation, subsequent chilling and then recovery. The leaf water content was simply calculated by the formula $[(1-($ leaf dry weight/leaf fresh weight $))] \times 100$.

Chilling injury was also evaluated by measuring cellular leakage. This was accomplished by cutting 4-mm leaf disks $(0.2$ $\mathrm{g}$ fresh weight) with a cork borer, then placing them in a $6-\mathrm{cm}-$ diameter polystyrene petri dish containing $5 \mathrm{~mL}$ of $1 \%$ sucrose and $1 \mathrm{~mm} 2-(\mathrm{N}$-morpholino)ethanesulfonic acid ( $\mathrm{pH}$ 6.5). The leaf disks were incubated at $25^{\circ} \mathrm{C}$ for $2 \mathrm{~h}$ with occasional shaking (Reyes and Jennings, 1994), and electrolyte leakage from the leaf disks into the bathing medium was measured subsequently using a conductivity meter (Cole-Parmer Instrument Co., Vernon Hills, Ill.). Because of the difference in background conductivity between treatments, data are expressed as changes in conductivity relative to an initial measurement. The electrolyte leakage just before the acclimation was used as the initial measurement. All treatments were replicated three times, and conductivity values were expressed on gram fresh weight basis.

LIPID PEROXIDATION. Lipid peroxidation was estimated by quantifying the amount of malondialdehyde (MDA) production using a slight modification of the thiobarbituric acid (TBA) method as previously described (Buege and Aust, 1978). The second true leaf from each plant $(0.5 \mathrm{~g})$ was harvested for each treatment period, and the tissues were homogenized using a mortar and pestle in 5 $\mathrm{mL}$ of $0.5 \% \mathrm{TBA}$ in $20 \%$ trichloroacetic acid. The homogenate was centrifuged at $20,000 \mathrm{~g}_{\mathrm{n}}$ for $15 \mathrm{~min}$, and the supernatant was collected. The supernatant was heated in a boiling water bath for $25 \mathrm{~min}$ and allowed to cool in an ice bath. Following additional centrifugation at $20,000 \mathrm{~g}_{\mathrm{n}}$ for $15 \mathrm{~min}$, the resulting supernatant was used for spectrophotometric determination of MDA. Absorbance at $532 \mathrm{~nm}$ for each sample was recorded and corrected for nonspecific turbidity at $600 \mathrm{~nm}$. MDA concentrations were calculated using a molar extinction coefficient of $156 \mathrm{mM}^{-1} \cdot \mathrm{cm}^{-1}$.

Chlorophyll (Chl) a Fluorescence AND QuANTUM yield MEASUREMENTS. Chl a fluorescence was measured in vivo at room temperature using a pulse amplitude modulation fluorom- eter (PAM-2000, Walz, Effeltrich, Germany). Before measuring fluorescence, leaves were adapted in darkness for 5 min to minimize fluorescence quenching associated with thylakoid membrane electron excitation (Krause et al., 1983). Minimal fluorescence yield, $\mathrm{F}_{0}$, was obtained upon excitation of the leaves with a weak measuring beam of $0.12 \mu \mathrm{mol} \cdot \mathrm{m}^{-2} \cdot \mathrm{s}^{-1}$ from a pulse light-emitting diode. Maximal fluorescence yield, $\mathrm{F}_{\mathrm{m}}$, was determined after exposure to a saturating pulse of white light to reduce all reaction centers. The ratio of variable to maximum fluorescence $\left(\mathrm{F}_{\mathrm{v}} / \mathrm{F}_{\mathrm{m}}\right)$ derived from the measurement was used as an estimate of the maximum photochemical efficiency of photosystem (PS) II (Butler, 1978). The quantum yield (Y) of electron transport through PS II ( $\mathrm{Y}=$ $\Delta \mathrm{F} / \mathrm{F}^{\prime}{ }_{\mathrm{m}}$ ) was calculated according to Genty et al. (1989).

Protein extraction. Frozen leaves $(0.5 \mathrm{~g})$ were pulverized in liquid $\mathrm{N}_{2}$ using a mortar and pestle, and then resuspended in 3 $\mathrm{mL}$ of $100 \mathrm{~mm}$ potassium phosphate buffer ( $\mathrm{pH} 7.5$ ) containing 2 mm ethylenediaminetetraacetic acid, $1 \%$ polyvinylpyrrolidone-40, and $1 \mathrm{~mm}$ phenylmethylsulfonyl fluoride. For ascorbate peroxidase (APX) assay, the extraction buffer also contained $5 \mathrm{~mm}$ ascorbate. The suspension was centrifuged at $15,000 \mathrm{~g}_{\mathrm{n}}$ for $20 \mathrm{~min}$ at $4{ }^{\circ} \mathrm{C}$ and the resulting supernatant was used directly as an enzyme source. For SOD assay, however, the supernatant was eluted through a Sephadex G-25 M minicolumn (PD-10; Pharmacia, Uppsala, Sweden) at 4 ${ }^{\circ} \mathrm{C}$ using $100 \mathrm{~mm}$ potassium phosphate buffer ( $\mathrm{pH}$ 7.5) to remove low molecular weight inhibitors (Anderson et al., 1995). Protein concentration was determined according to the method of Bradford (1976) using bovine serum albumin as a standard.

ENZYME ASSAYS. All enzymes were assayed in a 1-mL cuvette at 24 to $26^{\circ} \mathrm{C}$. Activity was linear with respect to time and enzyme concentration. Spectrophotometric determinations were carried out on a Shimadzu dual wavelength spectrophotometer model UV-2401 operated in the split beam mode.

SOD activity was determined based on its capacity to inhibit cytochrome c by superoxide generated by xanthine-xanthine oxidase reaction (Spychalla and Desborough, 1990). One unit of SOD was defined as the amount of enzyme which inhibited the rate of cytochrome c reduction by $50 \%$. CAT activity was assayed according to the method of Mishra et al. (1993) by monitoring the decline in absorbance at $240 \mathrm{~nm}\left(\varepsilon=36 \mathrm{M}^{-1 \cdot} \cdot \mathrm{cm}^{-1}\right)$ as a result of $\mathrm{H}_{2} \mathrm{O}_{2}$ degradation. APX activity was estimated with the method of Chen and Asada (1989) by monitoring the decline in absorbance at $290 \mathrm{~nm}$ as ascorbate $\left(\varepsilon=2.8 \mathrm{~mm}^{-1} \cdot \mathrm{cm}^{-1}\right)$ was oxidized. GR was measured with the method of Rao et al. (1996) by monitoring the decline in absorbance at $340 \mathrm{~nm}$ as NADPH $\left(\varepsilon=6.2 \mathrm{~mm}^{-1 \cdot} \cdot \mathrm{cm}^{-1}\right)$ was oxidized.

NATIVE POLYACRYLAMIDE GEL ELECTROPHORESIS AND ACTIVITY STAINING. Isozymes of CAT, SOD, APX, and GR were separated on nondenaturating polyacrylamide gels according to Laemmli (1970) with slight modifications. Equal amounts of protein extracts, mixed with bromophenol blue and glycerol to provide a final reaction concentration of $12.5 \%$. This mixture was loaded onto $7 \%$ (CAT) or $10 \%$ (SOD, APX, and GR) polyacrylamide gels. Proteins were separated by electrophoresis at $4{ }^{\circ} \mathrm{C}$ for $3 \mathrm{~h}$ with a constant current of $30 \mathrm{~mA}$. For APX, however, $2 \mathrm{~mm}$ ascorbate was added to the electrode buffer ( $\mathrm{pH} 8.3$ ) and the gel was prerun for $30 \mathrm{~min}$ before the sample was loaded (Mittler and Zilinskas, 1993). The gels were stained using methods prescribed for each enzyme.

SOD activity was detected according to the method of Rao et al. (1996). In some experiments, gels were incubated in $50 \mathrm{~mm}$ potassium phosphate buffer ( $\mathrm{pH} 7.8$ ) containing $3 \mathrm{~mm} \mathrm{KCN}$ or $5 \mathrm{mM} \mathrm{H}_{2} \mathrm{O}_{2}$ for $30 \mathrm{~min}$, before staining for SOD activity, to visualize $\mathrm{KCN}$ - and $\mathrm{H}_{2} \mathrm{O}_{2}$-sensitive isozymes (Britton et al., 1978). 
CAT activity was detected using the procedure of Anderson et al. (1995). APX and GR isozymes were visualized by the methods described by Rao et al. (1996).

Each staining reaction was stopped with $7.5 \%$ glacial acetic acid. The gels were then stored at $4{ }^{\circ} \mathrm{C}$ in plastic boxes containing $7.5 \%$ acetic acid solution until photographic recording.

\section{Results}

Physiological Responses to COld-ACClimation ANd Chilling. The leaf water contents in all plants were equivalent during $3 \mathrm{~d}$ of acclimation in cold-acclimated and nonacclimated leaves (Fig. 1A). However, subsequent chilling at $8{ }^{\circ} \mathrm{C}$ reduced leaf water contents progressively in nonacclimated leaves with increasing duration of chilling. Furthermore, water contents in these leaves

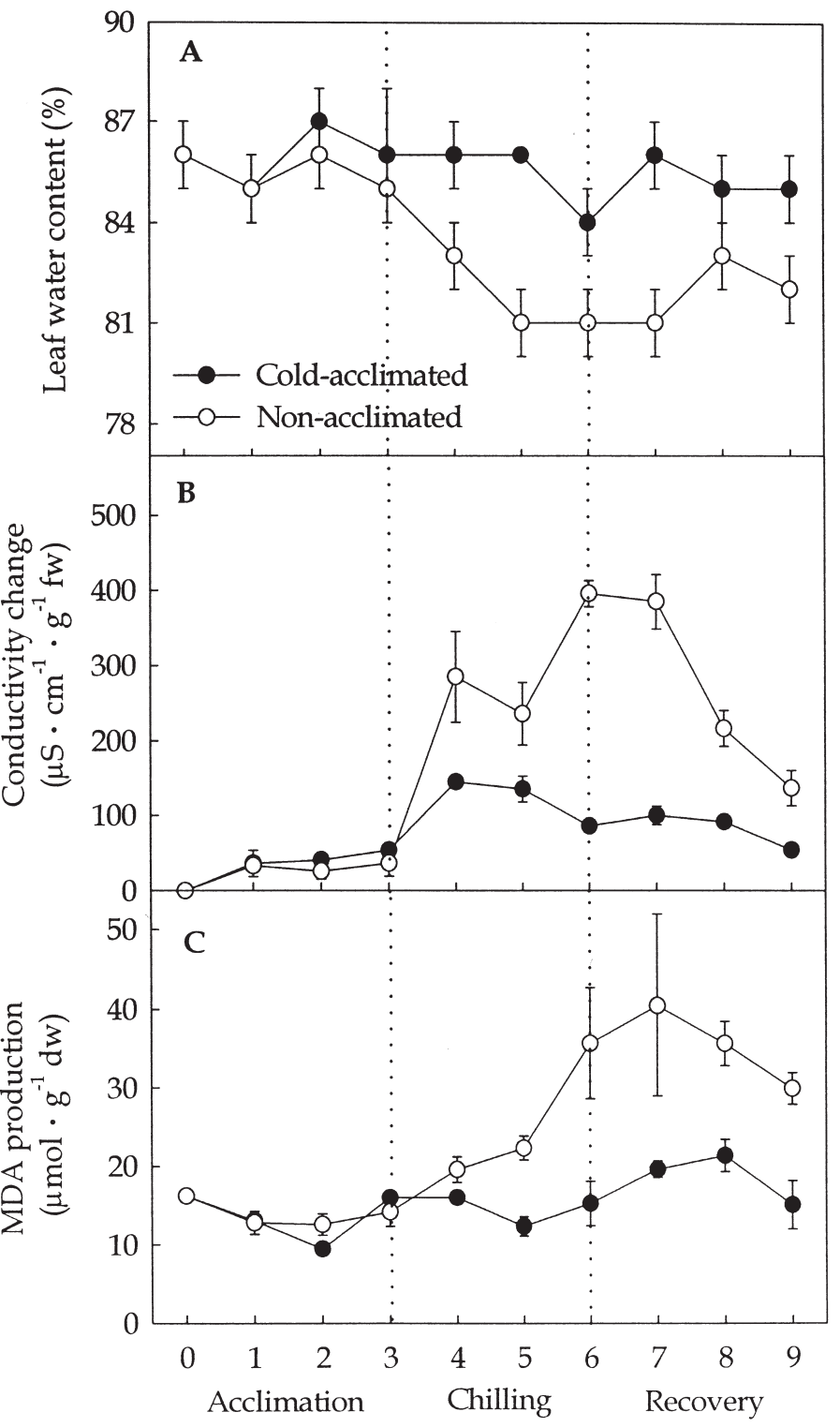

Days after treatment

Fig. 1. Changes in leaf water content $(\mathbf{A})$, cellular leakage (B), and lipid peroxidation (C) in cold-acclimated and nonacclimated cucumber leaves during acclimation, chilling, and recovery. The plants were exposed for $3 \mathrm{~d}$ at 15 (cold-acclimated) or $25{ }^{\circ} \mathrm{C}$ (nonacclimated), chilled for $3 \mathrm{~d}$ at $8{ }^{\circ} \mathrm{C}$, and allowed to recover at 25 ${ }^{\circ} \mathrm{C}$. Values are the mean $\pm \mathrm{SE}$ of three replications. In some cases, the error bar is obscured by the symbol. were not restored completely after $3 \mathrm{~d}$ of recovery at $25^{\circ} \mathrm{C}$. In contrast, cold-acclimated leaves did not wilt during the chilling process (Fig. 1A). Although in cold-acclimated leaves, leaf water contents decreased $3 \mathrm{~d}$ after chilling, the leaves recovered completely $1 \mathrm{~d}$ after terminating the chilling treatment.

There was no difference in cellular leakage between these leaves during the acclimation period (Fig. 1B). However, cellular leakage was consistently lower in cold-acclimated leaves than in nonacclimated leaves during the chilling period. After $3 \mathrm{~d}$ of chilling, cellular leakage from nonacclimated leaves was about four times higher than that of cold-acclimated leaves. Cellular leakage from chilled leaves declined when the plants were allowed to recover at $25^{\circ} \mathrm{C}$ (Fig. 1B). After $3 \mathrm{~d}$ in the recovery environment, cellular leakage from cold-acclimated leaves returned to the baseline levels observed during acclimation. Nonacclimated leaves, however, exhibited a higher level of cellular leakage after the recovery period than during acclimation.

LIPID PEROXIDATION. The level of MDA production was determined to estimate lipid peroxidation during acclimation, and subsequent chilling and recovery. Levels of MDA indicated that lipid peroxidation did not occur during acclimation in cold-acclimated and nonacclimated leaves (Fig. 1C). In nonacclimated leaves, however, lipid peroxidation occurred during chilling and increased with increasing chilling duration. The level of lipid peroxidation also increased during the first day of recovery and then declined thereafter (Fig. 1C). However, little or no lipid peroxidation occurred in cold-acclimated leaves during the chilling and the subsequent recovery.

Chl a Fluorescence AND QuANTum YIELd. During acclima-

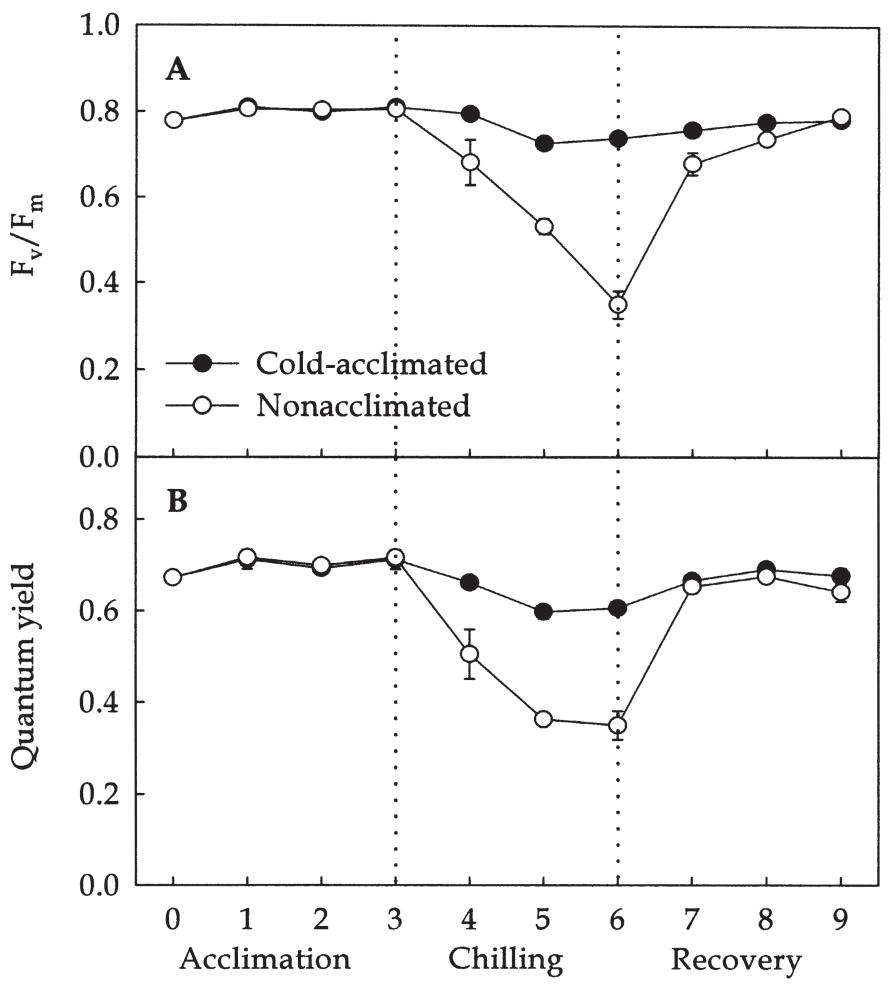

Days after treatment

Fig. 2. Changes in $F_{v} / F_{m}$ ratio $(\mathbf{A})$ and quantum yield $(\mathbf{B})$ in cold-acclimated and nonacclimated cucumber leaves during acclimation, chilling, and recovery. The plants were exposed for $3 \mathrm{~d}$ at 15 (cold-acclimated) or $25^{\circ} \mathrm{C}$ (nonacclimated), chilled for $3 \mathrm{~d}$ at $8{ }^{\circ} \mathrm{C}$, and allowed to recover at $25^{\circ} \mathrm{C}$. Values are the mean $\pm \mathrm{SE}$ of three replications. In some cases, the error bar is obscured by the symbol. 
tion, the Chl a fluorescence $\left(\mathrm{F}_{v} / \mathrm{F}_{\mathrm{m}}\right)$ values in cold-acclimated and nonacclimated leaves were only similar (Fig. 2A). However, subsequent exposure to chilling temperature rapidly reduced $\mathrm{Chl}$ a fluorescence in nonacclimated leaves, whereas the Chl a fluorescence in cold-acclimated leaves was slightly affected. The Chl a fluorescence of cold-acclimated and nonacclimated leaves was almost fully restored after $3 \mathrm{~d}$ of recovery.

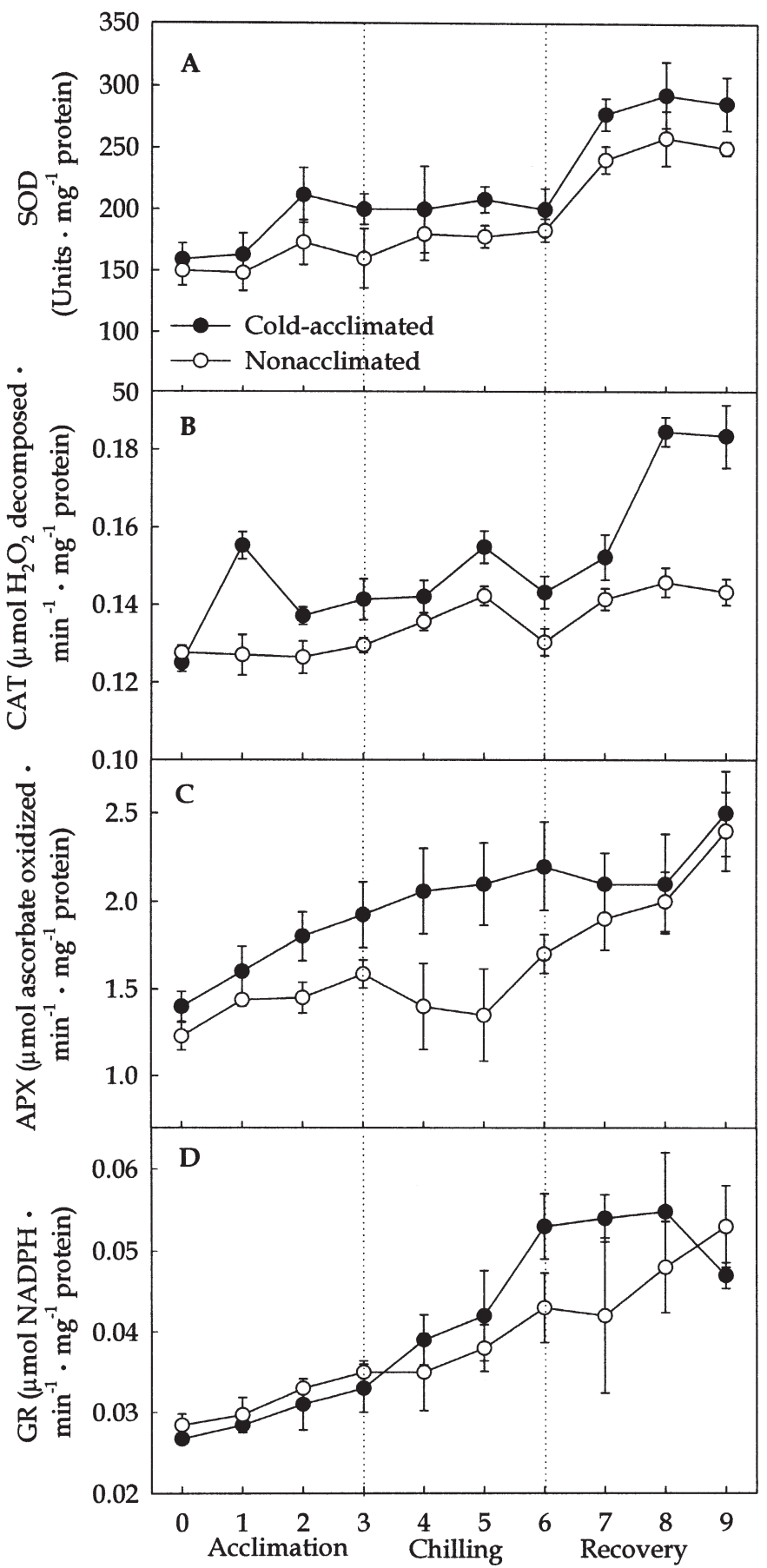

Days after treatment

Fig. 3. Changes in SOD (A), CAT (B), APX (C), and GR (D) activities in coldacclimated and nonacclimated cucumber leaves during acclimation, chilling, and recovery. The plants were exposed for $3 \mathrm{~d}$ at 15 (cold-acclimated) or 25 ${ }^{\circ} \mathrm{C}$ (nonacclimated), chilled for $3 \mathrm{~d}$ at $8{ }^{\circ} \mathrm{C}$, and allowed to recover at $25{ }^{\circ} \mathrm{C}$. Values are the mean $\pm \mathrm{SE}$ of three replications. In some cases, the error bar is obscured by the symbol.
Similar to the changes observed in Chl a fluorescence, quantum yields in nonacclimated leaves decreased rapidly during chilling and was mostly restored after the recovery period (Fig. 2B). In contrast, quantum yields of cold-acclimated leaves were not affected by chilling temperatures.

ANTIOXIDATIVE ENZYME ACTIVITY. Changes in antioxidative enzyme activities of SOD, CAT, APX, and GR activity in cold-acclimated and nonacclimated leaves during chilling and subsequent recovery are summarized in Fig. 3. The level of SOD activity was initially similar in all plants. However, $3 \mathrm{~d}$ after cold-acclimation and $2 \mathrm{~d}$ after chilling, SOD activity was higher in cold-acclimated leaves than in nonacclimated leaves (Fig. 3A). During recovery, SOD activity increased in both treatments, but the level of SOD activity in cold-acclimated leaves was higher than in nonacclimated leaves. CAT activity was higher in cold-acclimated leaves than in nonacclimated leaves during the acclimation period (Fig. 3B). CAT activity was higher in cold-acclimated leaves than in nonacclimated leaves during chilling and recovery. The effect of acclimation on CAT activity in cucumber leaves was most prominent during the period of recovery.

Similar to CAT, changes in APX activity were observed between cold-acclimated and nonacclimated leaves during acclimation and subsequent chilling (Fig. 3C). APX activity in cold-acclimated leaves was higher than in nonacclimated leaves toward the later stages of acclimation and this continued during chilling. However, there was no difference in APX activity between cold-acclimated and nonacclimated leaves after recovery. In general, no difference was observed in GR activity between cold-acclimated and nonacclimated leaves after chilling and at the end of the recovery period (Fig. 3D).

ANTIOXIDATIVE ISOZYME PROFILES. To relate changes in antioxidant isozyme patterns to chilling injury or tolerance in cold-acclimated and nonacclimated leaves, we analyzed SOD, CAT, APX, and GR isozymes on native polyacrylamide gels (Fig. 4). Two SOD isozymes were detected in cucumber leaves during acclimation and subsequent chilling regardless of acclimation temperature (Fig. 4A). Two additional SOD isozymes were detected in all leaves during recovery. All four isozymes were identified as Mn-SOD type because of their insensitivity to both $\mathrm{KCN}$ and $\mathrm{H}_{2} \mathrm{O}_{2}$ (Britton et al., 1978). Other SOD isozymes belonging to the $\mathrm{Cu} / \mathrm{Zn}-\mathrm{SOD}$ family

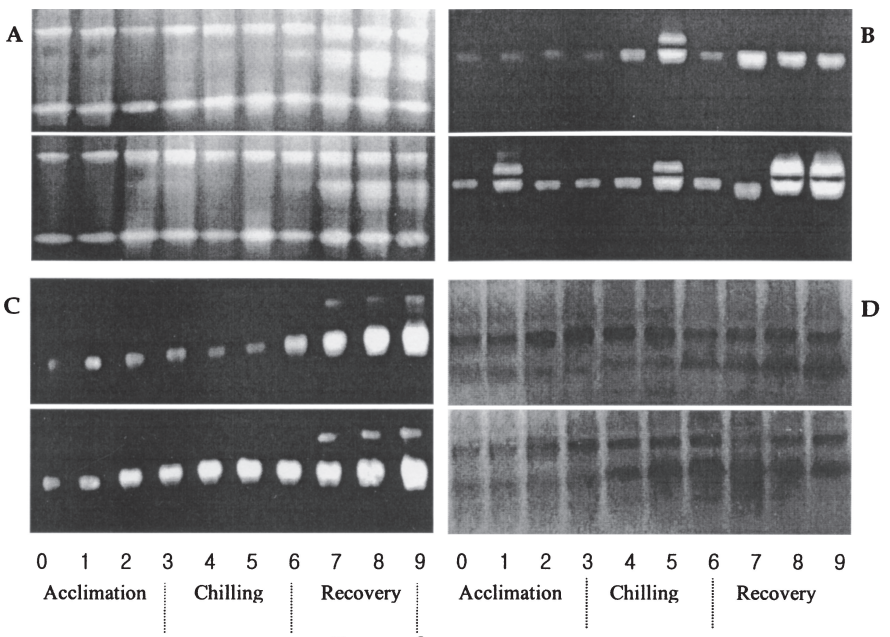

Days after treatment

Fig. 4. Changes in SOD (A), CAT (B), APX (C), and GR (D) isozyme profiles cold-acclimated (lower panel) and nonacclimated (upper panel) cucumber leaves during acclimation, chilling, and recovery. The plants were exposed for $3 \mathrm{~d}$ at 15 (cold-acclimated) or $25^{\circ} \mathrm{C}$ (nonacclimated), chilled for $3 \mathrm{~d}$ at $8{ }^{\circ} \mathrm{C}$, and allowed to recover at $25^{\circ} \mathrm{C}$. 
were also present, as indicated by their sensitivity to $\mathrm{KCN}$ and $\mathrm{H}_{2} \mathrm{O}_{2}$ (data not shown). Fe-SOD was not observed in any treatment. There was no significant difference in the level of the isozyme activity or their expression pattern in cold-acclimated and nonacclimated leaves during acclimation, chilling, and recovery.

Two isozymes of CAT were visualized and distinctive differences in isozyme expression pattern and activity were observed between cold-acclimated and nonacclimated leaves (Fig. 4B). The band intensity of CAT isozymes was higher in cold-acclimated leaves than in nonacclimated leaves during acclimation, subsequent chilling, and recovery. The CAT isozyme 1 (upper band) appeared one day after acclimation, $2 \mathrm{~d}$ after chilling, and two to $3 \mathrm{~d}$ into the recovery period in cold-acclimated leaves. In contrast, CAT isozyme 1 appeared only once ( $2 \mathrm{~d}$ after chilling) in nonacclimated leaves.

Three isozymes of APX were observed (Fig. 4C). APX isozyme 2 (middle band) was faint, but APX isozymes 1 and 3 were prominent. Isozymes 1 and 2 appeared only during the recovery period. The band intensity of APX isozymes was distinctly higher in cold-acclimated leaves than in nonacclimated leaves two and 3 $\mathrm{d}$ after acclimation and during chilling.

Three GR isozymes were observed in cucumber leaves in both acclimation temperatures (Fig. 4D), but GR isozyme 1 (upper band) was faint. The band intensity of GR isozyme 2 was higher in nonacclimated leaves than in cold-acclimated leaves during acclimation. In contrast, the band intensity of GR isozyme 3 was higher in cold-acclimated leaves than in nonacclimated leaves during chilling and 1 to $2 \mathrm{~d}$ after recovery.

\section{Discussion}

To understand the mechanisms of plant species responses to chilling, previous research had compared metabolic differences between chilling-susceptible and chilling-tolerant cultivars as model systems (Jahnke et al., 1991; Walker and McKersie, 1993). However, this model system was confounded by genetic differences between sensitive and tolerant species. To properly identify physiological responses to environmental stress such as chilling, the use of one cultivar that is chilling-sensitive, but can be acclimated, would be more appropriate.

Chilling initially damages the photosynthetic apparatus as a function of reduced $\mathrm{CO}_{2}$ fixation and altered fluorescence patterns of chlorophyll a (Walker et al., 1991). Other effects, including loss of water and chlorophyll contents, occur more gradually as leaf conductivity changes or leaves turn yellow (Koscielniak, 1993). Visual symptoms of chilling damage include waterlogged appearance, wilting, acceleration of senescence, and inhibition of seedling growth (Saltveit and Morris, 1990).

Cucumber plants exposed to chilling temperature exhibited all of these symptoms. However, cold-acclimated plants in this study were more tolerant to chilling stress than nonacclimated plants. This conclusion was based upon the variables measured including leaf water content, cellular leakage, lipid peroxidation, $\mathrm{F}_{\mathrm{v}} / \mathrm{F}_{\mathrm{m}}$ ratio, and quantum yield (Figs. 1 and 2). Cold-acclimated plants also recovered faster than nonacclimated plants. These results suggest that in cold-acclimated plants oxidative damage is reduced during chilling and, therefore, the plant recovers from injury. A similar acclimation phenomenon has been demonstrated in other low temperature-sensitive species, such as maize and tomato (Leipner et al., 1997; Venema et al., 2000).

It is known that chilling-induced AOS triggers a series of deleterious processes, such as lipid peroxidation and degradation of proteins and DNA damage in the cell (Halliwell and Gutteridge, 1986).
Lipid peroxidation, as a measure of cellular injury, was $\approx 2$-fold higher in nonacclimated plants compared to cold-acclimated plants during chilling and recovery (Fig. 1C). This confirms that chilling induced oxidative stress in cucumber plants. In maize seedlings, for example, there was a 2 -fold increase in lipid peroxidation in nonacclimated plants compared to nonstressed and cold-acclimated seedlings, during chilling (Prasad, 1996).

High SOD activity has been associated with stress tolerance in plants where overproduction of superoxide is involved (Bowler et al., 1992). SOD activity in cold acclimated spinach and wheat plants was higher compared to nonacclimated plants during exposure to low temperature (Scebba et al., 1999; Schöner and Krause, 1990). Induction of SOD activity by cold stress may not occur in all species. For instance, SOD activity in wheat subjected to chilling stress was not significantly modified by cold acclimation (Scebba et al., 1998). In our study, SOD activity was higher in cold-acclimated leaves than in nonacclimated leaves $3 \mathrm{~d}$ after acclimation, $2 \mathrm{~d}$ after chilling, and one and $3 \mathrm{~d}$ after recovery (Fig. 3A). Various SOD isozymes are expressed in different cells, tissues, or organelles and activities of the isozymes may be affected differently by chilling (Scandalios, 1993). Up to five SOD isozymes were observed during the course of this experiment on nondenaturing polyacrylamide gels, but none of them were significantly affected by cold acclimation (Fig. 4A). Similar to our results, new SOD isozymes were not detected in cold-acclimated wheat seedlings (Scebba et al., 1998). However, new SOD isozymes were induced in spinach by cold acclimation (Schöner and Krause, 1990).

The higher CAT activity (Fig. 3A) and band intensity (Fig. 4A) in leaves of cold-acclimated plants suggest a more efficient scavenging of $\mathrm{H}_{2} \mathrm{O}_{2}$, which resulted in better protection against peroxidation. Similarly, CAT activity in cold-acclimated material has been reported to remain similar to (O'Kane et al., 1996) or higher than (Anderson et al., 1995) that of nonstressed plants. In many cases, activity of CAT has been observed to decline in response to sudden exposure to chilling temperature without prior acclimation (Feierabend et al., 1992; Mishra et al., 1993). This was also true in chilled cucumber seedlings (Lee and Lee, 2000).

The important role of APX in relation to increasing oxidative tolerance has been observed in many plants (Feierabend et al., 1992; Gupta et al., 1993). In our study, APX activity was significantly affected by acclimation temperature and chilling treatment (Fig. $3 \mathrm{C})$. The high band intensity of APX isozymes from cold-acclimated plants supported the fact that APX activity was higher in cold-acclimated plants than in nonacclimated plants (Fig. 4C); i.e., the enzyme profile was similar, but expression level was elevated in cold-acclimated plants.

GR has been implicated as an important protection agent against oxidative damage in many plants (Foyer et al., 1991). In our study, however, there was no difference in total GR activity between coldacclimated or nonacclimated cucumber plants at any time during the duration of the experiment, except for $3 \mathrm{~d}$ after chilling (Fig. 3D). Exposure to low temperature resulted in altered GR isozyme profiles (Fig.4D). GR isozyme activity equalized the total GR activity in cucumber with or without cold acclimation (Fig. 4D).

Our results indicate that chilling-sensitive cucumber plants can be made cold-tolerant by cold acclimation which is paralleled by induced activities of antioxidative enzymes CAT and APX. However, the mechanism of chilling stress protection is complex and may act in concert with other physiological mechanisms which improve cellular membrane integrity, alter the composition of cellular fluids, or maintain the capability for physiological function under chilling temperature. 


\section{Literature Cited}

Anderson, M.D., T.K. Prasad, and C.R. Stewart. 1995. Changes in isozyme profiles of catalase, peroxidase, and glutathione reductase during acclimation to chilling in mesocotyls of maize seedlings. Plant Physiol. 109:1247-1257.

Basra, A.S. 2001. Crop responses and adaptations to temperature stress, p. 1-34. In: T.K. Prasad (ed.). Mechanisms of chilling injury and tolerance. Haworth Press Inc., New York.

Bowler, C.M., M. Van Montagu, and D. Inzé. 1992. Superoxide dismutase and stress tolerance. Annu. Rev. Plant Physiol. 43:83-116.

Bradford, M.M. 1976. A rapid and sensitive method for the quantitation of microgram quantities of protein utilizing the principle of protein-dye binding. Anal. Biochem. 72:248-254.

Britton, L., D.P. Malinowski, and I. Fridovich. 1978. Superoxide dismutase and oxygen metabolism in Streptococcus faecalis and comparison with other organisms. J. Bacteriol. 134:229-236.

Buege, J.A. and S.D. Aust. 1978. Microsomal lipid peroxidation. Methods Enzymol. 52:302-310.

Butler, W.L. 1978. Energy distribution in the photochemical apparatus of photosynthesis. Annu. Rev. Plant Physiol. 29:345-378.

Chen, G.X. and K. Asada. 1989. Ascorbate peroxidase in tea leaves: Occurrence of two isozymes and the differences in their enzymatic and molecular properties. Plant Cell Physiol. 30:987-998.

Erez, A., E. Cohen, and C. Frenkel. 2002. Oxygen-mediated cold-acclimation in cucumber (Cucumis sativus) seedlings. Physiol. Plant. 115: 541-549.

Feierabend, J., C. Schaan, and B. Hertwig. 1992. Photoinactivation of catalase occurs under both high- and low-temperature stress conditions and accompanies photoinhibition of photosystem II. Plant Physiol. 100: $1554-1561$.

Foyer, C.H., M. Lelandais, C. Galap, and K.J. Kunert. 1991. Effect of elevated cytosolic glutathione reductase activity on the cellular glutathione pool and photosynthesis in leaves under normal and stress conditions. Plant Physiol. 97:863-872.

Genty, B., J.M. Briantais, and N.R. Baker. 1989. Relationship between the quantum yield of photosynthetic electron transport and the quenching of chlorophyll fluorescence. Biochem. Biophys. Acta 990:87-92.

Gilmour, S.J., R.K. Hajera, and M.F. Thomashow.1988. Cold acclimation in Arabidopsis thaliana. Plant Physiol. 87:745-750.

Gupta, A.S., J.L. Heinen, A.S. Holaday, J.J. Burke, and R.D. Allen. 1993. Increased resistance to oxidative stress in transgenic plants that overexpress chloroplastic $\mathrm{Cu} / \mathrm{Zn}$ superoxide dismutase. Proc. Natl. Acad. Sci. USA 90:1629-1633.

Halliwell, B. and J.M.C. Gutteridge. 1986. Oxygen free radicals and iron in relation to biology and medicine: Some problems and concepts. Arch. Biochem. Biophys. 246:501-514.

Havaux, M. and A. Davaud. 1994. Photoinhibition of photosynthesis in chilled potato leaves is not correlated with a loss of photosystem II activity: Preferential inactivation of photosystem I. Photosynth. Res. 40:75-92.

Jahnke, L.S., M.P. Hull, and S.P. Long. 1991. Chilling stress and oxygen metabolizing enzymes in Zea diploperennis. Plant Cell Environ. 14: 97-104.

Koscielniak, J. 1993. Effects of low night temperature on photosynthetic activity of maize seedlings (Zea mays L.). J. Agron. Crop Sci. 171: 73-81.

Krause, G.H., T.M. Briantais, and C. Vernott. 1983. Characterization of chlorophyll fluorescence spectroscopy at $77 \mathrm{~K}$. I. $\Delta \mathrm{pH}$-dependent quenching. Biochem. Biophys. Acta 723:169-175.

Laemmli, U.K. 1970. Cleavage of structural proteins during the assembly of the head of bacteriophage $\mathrm{T}_{4}$. Nature 227:680-685.

Lee, D.H. and C.B. Lee. 2000. Chilling stress-induced changes of antioxidant enzymes in the leaves of cucumber: In gel enzyme activity assays. Plant Sci. 159:75-85.

Leipner, J., Y. Francheboud, and P. Stamp. 1997. Acclimation by suboptimal growth temperature diminishes photooxidative damage in maize leaves. Plant Cell Environ. 20:366-372.
Michalski, W.P. and Z. Kaniuga. 1982. Photosynthetic apparatus of chilling sensitive plants: Reversibility by light of cold- and dark-induced inactivation of cyanide-sensitive superoxide dismutase activity in tomato leaf chloroplasts. Biochem. Biophys. Acta 680:250-257.

Mishra, N.P., R.K. Mishra, and G.S. Singhal. 1993. Changes in the activities of anti-oxidant enzymes during exposure of intact wheat leaves of strong visible light at different temperatures in the presence of protein synthesis inhibitors. Plant Physiol. 102:903-910.

Mittler, R. and B. Zilinskas. 1993. Detection of ascorbate peroxidase activity in native gels by inhibition of the ascorbate-dependent reduction of nitroblue tetrazolium. Anal. Biochem. 212:540-546.

Oidaira, H., S. Satoshi, K. Tomokazu, and U. Takashi. 2000. Enhancement of antioxidant enzyme activities in chilled rice seedlings. Plant Physiol. 156:811-813.

O'kane, D., V. Gill, P. Boyd, and R. Burdon. 1996. Chilling oxidative stress and antioxidant responses in Arabidopsis thaliana callus. Planta 198:371-377.

Prasad, T.K. 1996. Mechanisms of chilling-induced oxidative stress injury and tolerance: Changes in antioxidant system, oxidation of proteins and lipids, and protease activities. Plant J. 10:1017-1026.

Rao, M.V., G. Paliyath, and D.P. Ormrod. 1996. Ultraviolet-B- and ozoneinduced biochemical changes in antioxidant enzymes of Arabidopsis thaliana. Plant Physiol. 110:125-136.

Reyes, E. and P.H. Jennings. 1994. Response of cucumber (Cucumis sativus L.) and squash (Cucurbita pepo L. var. melopepo) roots to chilling stress during early stages of seeding development. J. Amer. Soc. Hort. Sci. 119:964-970.

Salveit, M.E. and L.L. Morris. 1990. Overview on chilling injury of horticultural crops, p. 3-15. In: C.Y. Wang (ed.). Chilling injury of horticultural crops. CRC Press, Boca Raton, Fla.

Scandalios, J.G. 1993. Oxygen stress and superoxide dismutase. Plant Physiol. 101:7-12.

Scebba, F., L. Sebustiani, and C. Vitagliano. 1998. Changes in activity of antioxidant enzymes in wheat (Triticum aestivum L.) seedlings under cold acclimation. Physiol. Plant. 104:747-752.

Scebba, F., L. Sebustiani, and C. Vitagliano. 1999. Protective enzymes against activated oxygen species in wheat (Triticum aestivum L.) seedlings: Responses to cold acclimation. J. Plant Physiol. 155:762-768.

Schöner, S. and G.H. Krause. 1990. Protective systems against active oxygen species in spinach: Response to cold acclimation in excess light. Planta 180:383-389.

Spychalla, J.P. and S.L. Desborough. 1990. Superoxide dismutase, catalase, and $\alpha$-tocopherol content of stored potato tubers. Plant Physiol. 94:1214-1218

Terashima, I., S. Funayama, and K. Sonike. 1994. The site of photoinhibition in leaves of Cucumis sativus L. at low temperatures is photosystem I, not photosystem II. Planta 193:300-306.

Upadhyaya, A., T.D. Davis, R.H. Walser, A.B. Galbraith, and N. Sankhla. 1989. Uniconazole-induced alleviation of low-temperature damage in relation to antioxidant activity. HortScience 24:955-957.

Venema, J.H., L. Villerius, and P.R. van Hasselt. 2000. Effect of acclimation to suboptimal temperature on chilling-induced photodamage: Comparison between a domestic and a high-altitude wild Lycopersicon species. Plant Sci. 152:153-163.

Walker, M.A. and B.D. McKersie. 1993. Role of ascorbate-glutathione antioxidant system in chilling resistance of tomato. J. Plant Physiol. 141:234-239.

Walker, M.A., B.D. McKersie, and K.P. Pauls. 1991. Effects of chilling on the biochemical and functional properties of thylakoid membranes. Plant Physiol. 97:663-669.

Wang, C.Y. 1990. Alleviation of chilling injury of horticultural crops, p. 281-302. In: Wang C.Y. (ed.). Chilling injury of horticultural crops. CRC Press, Boca Raton, Fla.

Wise, R.R. and A.W. Naylor. 1987. The peroxidative destruction of lipids during chilling injury to photosynthesis and ultrastructure. Plant Physiol. 83:272-277. 